\title{
Fra effektiv til affektiv læring? Skjønnlitteratur og interkulturell kompetanse $\mathbf{i}$ fremmedspråksundervisningen
}

\author{
Hans Jacob Ohldieck* \\ Universitetet $i$ Sørørst-Norge, Norge
}

\begin{abstract}
Sammendrag
Den tiltakende globaliseringen vi har vært vitne til i de seneste tiårene, har økt behovet for interkulturell kompetanse i den norske skolen. Mens kulturdidaktikken tradisjonelt har satt andre kulturer som objekt for ens egen kunnskap, understrekes i dag verdien av gjensidig påvirkning og åpenhet gjennom prefikset inter. I denne artikkelen argumenterer jeg imidlertid for at toneangivende forskere innenfor fremmedspråksdidaktikken i Norge ikke har tatt konsekvensen av den begrepslige forskyvningen, og at man i praksis behandler andre kulturer som om de var transparente eller tilgjengelige for vår egen kunnskap. Mot denne bakgrunnen retter jeg oppmerksomheten mot skjønnlitteraturens didaktiske potensial, ut fra følgende problemstilling: Hvordan kan anvendelse av skjønnlitteratur i fremmedspråksundervisningen bidra til å styrke vår interkulturelle kompetanse $i$ globaliseringens tidsalder? Med støtte i poststrukturalistisk og postkolonial teori - særlig den franske filosofen Gilles Deleuze og den indiske litteraturteoretikeren Gayatri Spivak - argumenterer jeg for at en vektlegging av den skjønnlitterære affekten kan bidra til å skape større åpenhet overfor andre kulturer i fremmedspråksundervisningen, ved at det skapes brudd i leserens etablerte fordommer og forestillinger omkring «den andre».
\end{abstract}

Nøkkelord: Litteraturdidaktikk; affekt; fremmedspråksdidaktikk; poststrukturalisme; globalisering

\begin{abstract}
The increased strength of globalization processes that we have witnessed over the last decades, has served to highlight the relevance of intercultural competence within the Norwegian school system. Whereas traditional culture didactics posited other cultures as object for one's own knowledge, today the value of mutual influence and openness is underscored through the prefix inter. In this article, however, I argue that leading researchers within the field of foreign language didactics in Norway continue treating other cultures as if they were transparent to one's own knowledge. Against this background, I direct my attention towards the didactic potential of literature through the following question: In what ways may reading of literature in the foreign language classroom contribute to strengthening our intercultural competence in the age of
\end{abstract}

^Korrespondanse: Hans Jacob Ohldieck, Universitetet i Sørøst-Norge. Postboks 235, 3603 Kongsberg, E-post: Hans.J.Ohldieck@usn.no

(C) 2018 Hans Jacob Ohldieck. This is an Open Access article distributed under the terms of the Creative Commons Attribution 4.0 International License (http://creativecommons.org/licenses/by/4.0/), allowing third parties to copy and redistribute the material in any medium or format and to remix, transform, and build upon the material for any purpose, even commercially, provided the original work is properly cited and states its license. 


\section{Hans Facob Ohldieck}

globalization? Drawing on poststructuralist and postcolonial theories - in particular the French philosopher Gilles Deleuze and the Indian literary theorist Gayatri Spivak - I argue that the emphasis on literary affects may contribute to increasing our openness towards other cultures in the foreign language classroom, by rupturing established prejudices and views about «the other».

Keywords: Literature didactics; affects; foreign language didactics; poststructuralism; globalization

Mottatt: Mai, 2017; Antatt: Februar, 2018; Publisert: Mai, 2018

\section{Innledning}

Den tiltakende globaliseringen vi har vært vitne til i de seneste tiårene, har økt behovet for interkulturell kompetanse i den norske skolen. Dette standpunktet reflekteres på den ene siden i Kunnskapsløftet fra 2006, der det fremheves at «i en verden med økende mobilitet og digital samhandling er kompetanse i flere språk og interkulturell kompetanse en forutsetning for kommunikasjon og deltakelse på mange områder» (Lereplan i fremmedspråk, 2006). På den andre siden ser vektleggingen av interkulturell kompetanse ut til å være en del av dagens state-of-the-art innenfor det didaktiske forskningsfeltet både i Norge og Europa for øvrig (jf. for eksempel Rivers, 2010 og Haukås \& Thue Vold, 2012). Mens kulturdidaktikken tradisjonelt har satt andre kulturer som objekt for ens egen kunnskap, understrekes i dag verdien av gjensidig påvirkning og åpenhet gjennom prefikset inter. I denne artikkelen vil jeg imidlertid argumentere for at toneangivende forskere innenfor fremmedspråksdidaktikken i Norge ikke har tatt konsekvensen av den begrepslige forskyvningen, og at man i praksis behandler andre kulturer som om de var transparente eller tilgjengelige for vårt eget blikk.

Mot denne bakgrunnen vil jeg rette oppmerksomheten mot skjønnlitteraturen, med utgangspunkt i følgende problemstilling: Hvordan kan anvendelse av skjønnlitteratur $i$ fremmedspråksundervisningen bidra til å styrke vår interkulturelle kompetanse $i$ globaliseringens tidsalder? Problemstillingen går til kjernen av Ludvigsenutvalgets rapport (2016), der tre "fagovergripende kompetanser» - altså kompetansemål som gjelder alle fag - er beskrevet. Det siste av disse lyder: «å kunne utforske og skape (kritisk tenkning og problemløsning, kreativitet og innovasjon)» (4.3.6). Rapporten ligger til grunn for utarbeidelsen av ny læreplan, som ifølge Utdanningsdirektoratet vil tre i kraft høsten 2020. Overordnet del- verdier og prinsipper for grunnopplæringen av den nye læreplanen (Regjeringen, 2017) var imidlertid klar allerede i september 2017, og her er det skapende arbeidet mer eksplisitt knyttet til estetisk virke:

Elevene skal lære og utvikle seg gjennom sansning og tenkning, estetiske uttrykksformer og praktiske aktiviteter. [...] Kreative og skapende evner bidrar til å berike samfunnet. [...] Elever som lærer om og gjennom skapende virksomhet, utvikler evnen til å uttrykke seg på ulike måter, og til å løse problemer og stille nye spørsmål. 
[...] Vår estetiske sans utvikles i møte med ulike kulturelle uttrykk, og de bidrar til å løfte fram nye perspektiver» (1.4).

Vi vet foreløpig ikke hvordan hensynet til læring om «skapende virksomhet» vil nedfelles i læreplanen for de enkelte skolefagene, men siden "ulike kulturelle uttrykk» er fremhevet, vil det i forbindelse med fremmedspråkene være nærliggende å tenke i retning av skjønnlitteratur og annen estetisk produksjon fra målspråklandene. I denne artikkelen vil jeg særlig legge vekt på hvordan skjønnlitteraturens affektive kvaliteter kan skjerpe vår kritiske tenkning og bidra til å bryte opp våre etablerte forestillinger om andre kulturer.

Både i litteraturdidaktikken generelt og i den forgreningen som spesifikt er rettet mot fremmedspråksundervisningen, har ulike former for reader response-orientert teori i lang tid hatt en hegemonisk posisjon, noe som etter min mening har gått på bekostning av det affektive nivået. Jeg vil argumentere for at Reader responseteorienes vektlegging av lesersubjektet og meningen fremfor litteraturens affektive nivå, begrenser muligheten til å utforske skjønnlitteraturens interkulturelle dimensjon. Med særlig støtte i de poststrukturalistiske tenkerne Gilles Deleuze og Gayatri Spivak - som også har vært sentrale i utviklingen av postkolonial teori betrakter jeg affekten som primær i forhold til meningen. I tråd med dem betrakter jeg også affekten som et grunnleggende trekk ved kunsten og litteraturen, og til muligheten for å bryte opp etablerte forestillinger og maktrelasjoner gjennom estetiske uttrykk. Ved å trekke veksler på teoretiske perspektiver som tradisjonelt har hatt tydeligere forankring i litteraturvitenskapen enn i didaktikken, ønsker jeg på denne måten å bidra til nytenkning omkring forbindelsen mellom litteratur og interkulturell forståelse innenfor en norsk sammenheng, for slik å skape større åpenhet overfor andre kulturelle uttrykk, og dermed også grobunn for en reell interkulturell dialog.

Jeg beveger meg altså inn $\mathrm{i}$ et krysningspunkt mellom to didaktiske felt som i dagens fremmedspråksundervisning bør ses i relasjon til hverandre: litteraturdidaktikk og interkulturell forståelse. I forbindelse med litteraturdidaktikken vil jeg blant annet trekke veksler på Fenner (2001, 2008, 2011), Vestli (2008) og Olsbu (2014). Når det gjelder interkulturell forståelse innenfor en didaktisk horisont, vil jeg blant annet gå i dialog med Bugge (2011), Dypedahl \& Eschenbach (2014), Bøhn \& Dypedahl (2009), Thue Vold (2014) og Haukås \& Thue Vold (2012). Claire Kramsch sine arbeider vil dessuten være en sentral internasjonal referanse både når det gjelder litteraturdidaktikk og interkulturell kompetanse.

Med støtte i Olsbu (2014) åpner jeg artikkelen med en diskusjon av det litteraturdidaktiske feltet i dag. Deretter diskuterer jeg litteraturdidaktikk og interkulturell kompetanse i lys av Deleuze og Kramsch, før jeg mer spesifikt bringer diskusjonen innenfor en postkolonial ramme hvor Spivak blir teoretisk hovedreferanse. Oppmerksomheten vil først og fremst være rettet mot didaktiske diskusjoner innenfor en norsk sammenheng, men jeg vil også trekke veksler på internasjonale 


\section{Hans Facob Ohldieck}

perspektiver der de er relevante. Artikkelen har et teoretisk siktemål og er ikke empirisk fundert i form av dataanalyser. Samtidig er det et mål at den teoretiske diskusjonen som føres frem, skal kunne danne grunnlag for fremtidige empiriske undersøkelser.

\section{Litteraturdidaktikken i dag}

Inger Olsbu (2014) har kartlagt dagens litteraturdidaktiske forskningsfelt ved eksplisitt å basere seg på Bredella (2004), og hun har identifisert følgende hovedkategorier: «1) The task-based approach, 2) the stylistic approach, 3) the experiential approach, and 4) the intercultural approach». Olsbu understreker at disse kategoriene sjelden opptrer $\mathrm{i}$ "ren» form og at de kan kombineres på ulike måter. Like fullt vil jeg anvende dem som ramme for den videre diskusjonen, og jeg vil derfor gi en kort sammenfatning. ${ }^{1}$

Det Olsbu omtaler som «the task-based approach» innebærer at skjønnlitteraturen først og fremst utgjør en stimulus for ulike typer aktiviteter, som strekker seg fra konkrete, individuelle oppgaver omkring tekstforståelse og lignende, til en mer eksperimentell "creative writing» og videre til interaktive øvelser som for eksempel rollespill. Grunntanken er at skjønnlitteraturen kan bidra til å stimulere språklæringens ulike deler (lytting, tale, lesing, skriving og spontan kommunikasjon), mens skjønnlitteraturens eget erkjennelsespotensial spiller en mindre vesentlig rolle.

«The stylistic approach» fokuserer på hvordan mening skapes i en litterær tekst. Ved at eleven blir oppmerksom på den litterære tekstens subtile nyanser, ønsker man å stimulere til videre lesning. Det didaktiske hovedpoenget er at eleven - gjennom lesingen av skjønnlitteraturens rike og finmaskede språk - kan utvikle sitt eget blikk for språklige nyanseforskjeller generelt. Olsbu påpeker at skjønnlitteraturens språklige dimensjon vektlegges, mens estetiske kvaliteter kommer i skyggen.

«The experiential approach» fokuserer på møtet mellom leser og verk, og særlig på hvordan møtet med en litterær tekst kan utfordre våre etablerte perspektiver og slik igangsette ny meningsproduksjon gjennom ulike former for dialog mellom leser og tekst. Dannelsesperspektivet har tradisjonelt vært viktig innenfor denne kategorien, som legger opp til et holistisk litteratursyn: "In the experiential approach the value of the literary text resides in its meaningfulness, and reading literature is seen as an activity that involves the whole person (feelings, attitudes, reflections)" (Olsbu, 2014, s. 5). Til tross for vektleggingen av «det hele mennesket» er imidlertid meningen i sentrum i de aller fleste bidragene innenfor denne kategorien, på bekostning av det affektive og estetiske erkjennelsespotensialet.

«The intercultural approach» fokuserer på hvordan skjønnlitteraturen kan bringe eleven i møte med kulturelle perspektiver som er ulike ens egne, for slik å øve opp

${ }^{1}$ Olsbu diskuterer dessuten det hun kaller «the canonical approach» og "the no-literature approach». Disse er imidlertid mindre relevante for denne artikkelens siktemål, og vil derfor ikke bli tematisert. 
elevens evne til å respektere forskjeller. Det ligger et dialogisk prinsipp til grunn også her, og det interkulturelle perspektivet innebærer at eleven erfarer at også hun/han er farget av visse forutsetninger som lar seg modifisere gjennom møtet med andre kulturer. En eksplisitt ambisjon er følgelig at man skal kunne betrakte sitt eget kulturelle ståsted i et nytt og relativiserende lys.

Hvis vi knytter de ulike didaktiske kategoriene til litteraturteoretiske referanser, vil vi se at både "the task-based approach» og "the experiential approach» $\mathrm{i}$ stor grad er forankret i ulike former for reader response-teori, der både Louise M. Rosenblatt, Wolfgang Iser, Stanley Fish, David Bleich og Norman Holland er tilbakevendende referanser. "The stylistic approach» har røtter i russisk formalisme og pragerstrukturalismen, med lingvisten Roman Jakobson som en sentral referanse. "The intercultural approach» er påvirket av reader response-teorier, men henter også impulser fra andre teoretiske og filosofiske felt, som blant annet hermeneutikk og postkolonial teori. I tillegg kommer impulser fra kommunikasjonsvitenskap og andre fagfelt, som på ulike vis gjør seg gjeldende innenfor de nevnte kategoriene.

Reader response-teoriens sentrale posisjon underbygges av Vestli (2008), som samtidig viser at litteraturdidaktikken også historisk har vært tett forbundet med reader response-teori i ulike versjoner. Med støtte i Paefgen (1999) beskriver hun hvordan litteraturdidaktikken utviklet seg på 60- og 70-tallet, «med utgangspunkt i bl.a. aksentforskyvningen fra den verkimmanente metode til en historisk-sosiologisk tilnærming, som en følge av den oppblomstrende interessen for resepsionsestetikk og kommunikasjonsvitenskap» (2008, s. 8). Et hovedmoment i ulike former for reader response-teori er at leseren tillegges en sentral rolle, i sterk kontrast til hva som var tilfellet innenfor nykritikken, en verkimmanent retning som dominerte litteraturstudiene i USA fra 1920- til 1960-årene, og som også var sentral i Norge.

Innenfor en filosofisk horisont springer reader response-teorien ut av en fenomenologisk tradisjon, der det vesentlige er hvordan verden og tingene - og mer spesifikt verket - fremtrer for den subjektive bevisstheten. Verket eksisterer altså ikke uavhengig av individuelle leseres erfaringer, et perspektiv som bryter tvert med nykritikkens vektlegging av det selvstendige, autonome verket. Ifølge reader response-teorien skaper leseren mening gjennom å knytte det skrevne til ens egne erfaringer.

I en norsk sammenheng har Vestli markert seg som eksponent for reader response-teori innenfor "the task-based approach». På tilsvarende vis er reader response-teori grunnleggende for Signe Mari Wiland - blant annet i Poetry: Prima Vista. Reader-Response Research on Poetry in a Foreign Language Context (2007) og Anne-Brit Fenner, som videre knytter an til både Mikhail Bakhtin og mer generelt en hermeneutisk tradisjon representert ved Hans-Georg Gadamer og Paul Ricoeur. Både Wiland og Fenner klassifiseres innenfor kategorien for «experiential approach» av Olsbu, og i motsetning til hva tilfellet er for Vestli, er ikke det konkrete oppgavefokuset primært i deres interesse for litteratur. Fenner utforsker 


\section{Hans Facob Ohldieck}

for eksempel hvordan skjønnlitteraturen kan bidra til å bryte med gjenkjennelsens pedagogiske struktur, som ifølge henne har fătt en altfor dominerende posisjon i lærebøkene, ved at man konstruerer situasjoner og dialoger basert på ungdommers dagligliv i Norge og målspråkområdet. Som motsats til dette, kan skjønnlitteraturen gi en verdifull erfaring av det fremmede, ifølge Fenner, som slik nærmer seg et av litteraturvitenskapens grunnbegreper: ostranenie, underliggjøring, som Viktor Sjklovskij knyttet til skjønnlitteraturens vesen $\mathrm{i}$ 《Litteraturen som grep» fra 1914.

Spørsmålet er likevel om det teoretiske/filosofiske grunnlaget Fenner baserer seg på er egnet til å bryte gjenkjennelsens struktur, all den tid både reader response-teorien og hermeneutikken setter subjektet og meningen i fokus. I Wolfgang Isers versjon (1980) av førstnevnte er det nødvendig å «fylle tekstens tomrom» ut fra ens egne subjektive erfaringer før verket fremtrer som estetisk objekt. Selv om Gadamer fornyer hermeneutikken på vesentlige områder, og selv om Ricoeur vektlegger selvet som $i p s e-$ et selv som uopphørlig er i endring gjennom den kontinuerlige eksponeringen for «den andre» - er det fortsatt meningen som er i sentrum også her. Ifølge en poststrukturalistisk tenker som Gilles Deleuze rystes dermed verken subjektet, bevisstheten eller meningen $\mathrm{i}$ en slik grad at man kan skape en reell åpenhet for annetheten. Mot mening og fortolkning setter Deleuze affekten, og siden denne er sentral i min egen diskusjon av de interkulturelle og litteraturdidaktiske feltene, skal vi se litt nærmere på hva den innebærer i Deleuzes forståelse. Vi skal imidlertid gå veien om Claire Kramsch.

\section{Deleuze, Kramsch og poststrukturalistiske perspektiver}

Blant dem som trekker veksler på poststrukturalistiske perspektiver innenfor det didaktiske feltet, er nemlig Claire Kramsch, som fortrinnsvis henter impulser fra Michel Foucault og Jacques Derrida. Kramsch forfølger også poststrukturalistisk tenkning i ulike postkoloniale tapninger idet hun knytter skjønnlitteraturen og det interkulturelle aspektet ved språklæring sammen i begrepet om «third place» (1993) og senere også "symbolic competence» (2010). "Third place» er inspirert av Homi Bhabhas tenkning omkring «third space» og viser til det tredje rommet - eller mellomrommet, in-between (Bhabha, 2010 [1994]) - hvor det interkulturelle møtet finner sted, og hvor hybride identiteter kan oppstå gjennom gjensidig påvirkning. ${ }^{2}$ Mens begrepet om «third place» fortsatt er forankret i møter mellom nasjonale kulturer i Kramsch sin versjon fra 1993, gir det på 2000-tallet stadig mindre mening å snakke

\footnotetext{
${ }^{2}$ Bhabha skriver i denne sammenhengen at «it is the 'inter' - the cutting edge of translation and negotiation, the inbetween space - that carries the burden of the meaning of culture [...] and by exploring this Third Space, we may elude the politics of polarity and emerge as the others of our selves» (2010, s. 56). Det er med andre ord i det interkulturelle mellomrommet vi kan overvinne fastlåste fordommer, og slik kan vi også utvide vår kulturelle horisont, ved å la oss påvirke av «den andre».
} 
om denne typen monolittiske størrelser. Kramsch fremhever derfor i tiltakende grad den diskursive kvaliteten ved kulturbegrepet, det vil si det foranderlige og heterogene mangfoldet av ulike kulturelle diskurser, som ikke lenger må forstås primært innenfor nasjonale rammer.

I et slikt scenario er det ifølge Kramsch nødvendig å utvikle en symbolsk kompetanse, noe som innebærer at man blir i stand til å lese og syntetisere tegn innenfor et utvidet kulturelt register. Dette får også konsekvenser for didaktikken: «The symbolic dimension of intercultural competence calls for an approach to the training of language teachers that is discourse-based, historically grounded, aesthetically sensitive, and that takes into account the actual, the imagined and the virtual worlds in which we live» (2010, s. 366). Som vi ser av Kramsch sitt sitat, blir den symbolske, diskursbaserte dimensjonen ekstra viktig i utviklingen av interkulturelle perspektiver, siden den muliggjør en åpenhet og sensibilitet overfor dagens kompliserte og globaliserte virkelighet. Det som imidlertid er mest interessant i mitt perspektiv, er betoningen av det estetisk sensitive, og at man må ta inn "the actual, the imagined and the virtual worlds in which we live» (Kramsch, 2010, s. 366).

Kramsch har spøkefullt uttalt at hun er skeptisk til begreper som ikke lar seg oversette til fransk, ${ }^{3}$ og i forbindelse med den estetiske dimensjonen ved den interkulturelle kompetansen er hun i godt fransk selskap. Her ligger hun nært Jacques Rancières begrep om "fordelingen av det sanselige» - le partage du sensible (2000) som forutsetter at det ligger en symbolsk-estetisk kamp til grunn for hva som får komme til uttrykk innenfor diskursens orden. «Fordelingen av det sanselige» er med andre ord et begrep som tar på alvor sansningens betydning både for erkjennelsen og for psykiske strukturer. På tilsvarende vis mener jeg Kramsch ligger nært Deleuzes tanke om at vi må utvikle en estetisk-politisk sensibilitet og subjektsforståelse dersom vi skal kunne fungere aktivt og skapende innenfor en globalisert virkelighet. Forbindelsen til Deleuze er også til stede i omtalen av de aktuelle og virtuelle verdenene, der sistnevnte begrep får en tvetydig status i Kramsch sin anvendelse, siden det knytter an til både cyberspace og til Deleuzes begrep om virtualiteten.

I Deleuzes perspektiv er virtualiteten et felt av muligheter for at noe kan oppstå eller få sin tilblivelse, og i omtalen av dette feltet henter Deleuze impulser fra både Spinoza, Leibniz, Nietzsche og Bergson. Deleuzes interesse for estetiske uttrykk er forbundet med hvordan disse kan bryte opp tilstivnede erfaringsmønstre for slik å skape åpning for «alle disse menneskets ikke-menneskelige tilblivelser» (2008, s. 496). Disse tilblivelsene er mulige fordi virtualiteten viser til et før-subjektivt nivå, og dermed tenkes også subjektet som prosessuelt $\mathrm{i}$ en mer radikal forstand enn både det fenomenologiske individfokuset og den hermeneutiske sirkelen kan ta høyde for. Den deleuzianske formen for subjektivering finner gjenklang i Kramsch sin symbolske dimensjon: «our historical and subjective self gets constructed across utterances and turns-at-talk between the self we have just been and the self we might still become»

${ }^{3}$ Kommentaren er fra et foredrag hun holdt i Roskilde, og som ble lagt ut på YouTube i januar 2013, under tittelen «Identity vs. Subjectivity»: https://www.youtube.com/watch?v=XWLPm9hVmU4 


\section{Hans facob Ohldieck}

(Kramsch, 2006, s. 23). Også her er det snakk om en subjektiveringsprosess som peker mot vorden eller tilblivelse, der selvet dannes gjennom måten det fletter sammen ulike diskursive felt på, ved å forholde seg til «fluid discourse processes» (Kramsch, 2014, s. 308).

Hvordan kan så de estetiske uttrykkene bryte opp etablerte forestillinger og fordommer? Både Deleuze og Kramsch vektlegger i denne sammenhengen affektens rolle, en kroppslig erfaring som overskrider rammen for mening og bevissthet. Dette perspektivet er ikke unikt innenfor det humanistiske feltet, som på mange måter har opplevd en «affektiv vending» på 2000-tallet, og det er heller ikke unikt innenfor det didaktiske feltet, der affekten blant annet kan knyttes til Daniel Shanahan (1997). Læringssynet til de fleste av didaktikkforskerne som fremhever affekten, er imidlertid langt mer instrumentelt og lingvistisk basert enn estetisk orientert. Det vil si: Kunst og litteratur betraktes først og fremst som stimuli for elevene, slik at de skal bli motiverte for det de «egentlig» skal lære i fremmedspråksundervisningen, nemlig gloser og grammatikk. ${ }^{4}$

Kramsch er derimot interessert i hvordan affekten kan skape en reell kommunikasjonsflate med andre mennesker og kulturer, og i en diskusjon omkring affekten skriver hun blant annet som følger: "personal stories can provide a 'narrative hook' to engage students' imagination and emotional investment to empathize with characters even if they cannot fully understand experiences they have not themselves lived through" (2014, s. 308). Jeg synes dette er en spennende tanke, samtidig som sitatet er symptomatisk for forskjellen mellom Kramsch og Deleuze når det gjelder det affektive nivået. Kramsch knytter nemlig affekten til følelser og empati i langt større grad enn Deleuze, som i Cinéma 1 - L'image-mouvement (1983) tvert imot er skeptisk til hvordan film og litteratur kan bidra til å opprettholde status quo gjennom følelsesmessig katharsis, der Hollywood-filmens klisjé-repertoar blir et emblematisk uttrykk.

Mens følelser er underlagt en subjektiv eller personlig posisjon, er Deleuzes affekt forbeholdt mer dyptgående, intense og opprivende hendelser som bryter med subjektets koherens eller integritet. ${ }^{5}$ Deleuze tilskriver i denne sammenhengen estetiske uttrykk en type erkjennelsespotensial som overskrider rasjonelle kategorier, og som er primært i forhold til den subjektive bevisstheten. Dette er tydelig formulert i blant annet Mille plateaux (A Thousand Plateaus), der Félix Guattari er medforfatter:

For the affect is not personal feeling, nor is it a characteristic; it is the effectuation of a power of the pack that throws the self into upheavel and makes it reel. Who has

\footnotetext{
${ }^{4}$ Jeg viser til Kramsch sin diskusjon av dette temaet i foredraget «Identity vs. Subjectivity»: https:// www.youtube.com/watch?v=XWLPm9hVmU4

${ }^{5}$ I forlengelsen av Deleuze betoner også Brian Massumi skillet mellom affekter og følelser: "Affect is most often used loosely as a synonym for emotion. But one of the clearest lessons of this first story is that emotion and affect - if affect is intensity - follow different logics and pertain to different orders. An emotion is a subjective content, the sociolinguistic fixing of the quality of an experience which is from that point onward defined as personal» (2002, s. 27-28).
} 
not known the violence of these animal sequences, which uproot one from humanity, if only for an instant, making one scrape at one's bread like a rodent or give one the yellow eye of the feline? A fearsome involution calling us toward unheard-ofbecomings (1987, s. 240).

Her handler det ikke om affekt som følelse eller empati, men som kroppslig løsrivelse fra det subjektive og det menneskelige, forstått som dominerende, strukturerende diskurser og verdier som sammen danner det meningsparadigmet vi til vanlig befinner oss innenfor. Affekten gjør seg altså gjeldende som intensitet på et før-bevisst nivå, og når forfatteren ifølge Deleuze er "en lege for seg selv og verden», mens skjønnlitteraturen er et "helbredende prosjekt» som bidrar til «å frigjøre livet fra hvor det enn er innesperret» (2005, s. 215), må også dette forstås innenfor det samme affektive registeret. For Deleuze er skjønnlitteraturens mål å skape affekter, og slik bringes vi altså i møte med bevissthetens utside, det virtuelle feltet av muligheter som ennå ikke er realisert.

Hvis vi vender tilbake til Olsbu sine kategorier, vil det være naturlig å plassere Deleuzes litteratursyn både innenfor "the experiential approach» og «the intercultural approach». Når det gjelder plasseringen i førstnevnte kategori, må det tas forbehold om at "experience» $i$ en deleuziansk forståelse er ulik den fenomenologiske. Som vi har sett, er affekten primær for Deleuze, ikke meningen, slik tilfellet er innenfor denne kategoriens sentrale referanser i Olsbus utlegning. Samtidig er det viktig å understreke at affekten er uløselig forbundet med tenkning: Som bruddmoment åpner den for ny tenkning og ny mening ut fra andre koordinater, samtidig som vedvarende åpenhet for nye affekter hindrer gjenetablering av hegemoniske narrativer.

Affekten kan skape en radikal åpenhet for annetheten innenfor en estetisk horisont, og dette innebærer potensielt også en åpning for annetheten innenfor kulturelle termer. Det vesentlige i Deleuze sitt perspektiv er at en slik åpenhet nødvendigvis må bære i seg en kroppslig erfaring som overskrider meningen, et perspektiv som praktisk talt er fraværende i pågående diskusjoner omkring interkulturell språkbevissthet, $i$ hvert fall i en norsk sammenheng.

\section{Interkulturell kompetanse og «den andres» perspektiv}

Vektleggingen av interkulturell kompetanse kom ifølge Skulstad (2012) inn i læreplanen for engelskfaget på 90-tallet, selv om begrepet ikke ble anvendt direkte. Nå begynte man for alvor å ta inn over seg at møtet med andre kulturer nødvendigvis bærer merke av ens egen kulturelle horisont eller habitus, og at den tradisjonelle kulturkunnskapen derfor måtte erstattes av en mer dynamisk interkulturell forståelse, for slik å ta til etterretning at påvirkningen skjer begge veier (Fenner, 2008). Det ble tydeligere at man måtte utvikle en evne og vilje til å decentre (Byram, 1997), å skifte perspektiv, for på denne måten å erfare at også ens eget kulturelle ståsted er av kontingent eller historisk betinget karakter. Utover på 2000-tallet fikk det interkulturelle aspektet imidlertid tydeligere status som eget kompetansemål, og i didaktisk forskning er det stor enighet om at denne dreiningen har sammenheng med 


\section{Hans Facob Ohldieck}

tiltakende globalisering. ${ }^{6}$ Leth Andersen, Lund \& Risager skriver for eksempel som følger i 2006 (s. 8): «Foreign language learning and teaching should not only focus on communicative competence in a national context but also on intercultural competencies in a complex, multicultural world». En globalisert virkelighet tvinger altså frem endringer i synet på fremmedspråksundervisningen ved at fokuset på språkkompetanse nå utvides med et interkulturelt perspektiv. Eller med Kramsch sine ord:

[Intercultural learning] characterizes a form of language learning that is less focused on approximating a native speaker linguistic or pragmatic norm than it is based on the subjective experience of the language learner engaged in the process of becoming bi- or multilingual and struggling with another language, culture and identity (2006, s. 15).

Den interkulturelle dreiningen som Kramsch skisserer, er dessuten tydelig i Europarådets rammeverk for europeisk fremmedspråksundervisning fra 2001, Common Framework of Reference for Language, selv om flere vil hevde at fokuset på interkulturell kompetanse er i overkant summarisk i dette dokumentet (se for eksempel Risager, 2004; Tornberg, 2013 og Thue Vold, 2014).

Når det gjelder interkulturell forståelse innenfor en didaktisk horisont, har Karen Risager, Michael Byram og Claire Kramsch øvd avgjørende innflytelse på den norske forskningen. Hans-Erik Bugges artikkel «Utvikling av interkulturell kompetanse og språkopplæring - to sider av samme sak» - publisert i Fremmedspråksenteret tidsskrift Communicare (1/2011) - er illustrerende i så måte. Her beskriver Bugge hvordan man i en norsk sammenheng kan trekke veksler på undervisningsmodellen til Michael Byram (1989, 1997, 2008), som Bugge mener er særlig godt egnet til å oppfylle målene i læreplanen. «Spørsmålet», skriver Bugge, er "hvordan vi best fremmer interesse for fremmede kulturer samt bidrar til at elevene utvikler innsikt i egne livsvilkår og egen identitet» (s. 6). Han foreslår blant annet å bruke «tekster og annet undervisningsmateriale som beskriver målspråklandenes levesett og verdiforestillinger», for på den måten å kunne sammenligne ens egen nasjonale identitet med ditto i målspråklandet. I tillegg tar han til orde for å vektlegge viktige historiske hendelser i norske samfunnsforhold - deriblant «nasjonalstatsutviklingen på 1800-tallet, den andre verdenskrig og etterkrigstiden» (s. 9) - for i neste omgang å sammenligne disse med tilsvarende i målspråklandet. Også «norsk geografi med fjord og fjell, grisgrendte strøk og befolkningstette byområder» (s. 9) kan sammenlignes med geografiske forhold i målspråklandet, mens andre "typiske tema kan være kjønnsrolle- og familiemønster, ungdom og skole samt fritid» (s. 9). Autentiske tekster tillegges ikke

${ }^{6}$ I likhet med Claire Kramsch (2014) baserer jeg meg på Blommaerts (2010) definisjon av globalisering som "shorthand for the intensified flows of capital, goods, people, images and discourses around the globe, driven by technological innovations mainly in the field of media and information and communication technology, and resulting in new patterns of global activity, community organization and culture» (s. 13). 
vekt, og jeg mener man bør spørre seg hvorvidt de eksemplene Bugge anfører er egnet til å bryte med det tradisjonelle turismeperspektivet som har vært dominerende innenfor fremmedspråkene i flere tiår allerede, og som blant andre Fenner (2012) og Eide (2012) har kommentert utførlig.

I min lesning av Bugges strategier ligger disse generelt tett opp til det Dypedahl og Eschenbach (2014) omtaler som en "essensialistisk kulturtilnærming», en tilnærming som «forenkler og kan føre til stereotypier»(s. 158), og Bugge er ikke alene om å knytte an til essensialistiske kulturperspektiver i en norsk kontekst. Når Dypedahl og Eschenbach beskriver slike former for tilnærming, er det nemlig som en problematisering av den implisitte essensialismen i det som kanskje er den mest siterte definisjonen av interkulturell kompetanse i en norsk didaktisk sammenheng: «evnen til å kommunisere hensiktsmessig og passende med mennesker som har en annen kulturell bakgrunn» (Bøhn \& Dypedahl, 2009, s. 12). Gjennom en kritisk lesning av denne definisjonen, forsøker Dypedahl og Eschenbach - som også baserer seg på Byram - å bevege seg i retning av et mer dynamisk kulturbegrep, som vil ligge nærmere Kramsch sin betoning av kulturell heterogenitet. I lys av dette er det verdt å merke seg at de to forskerne samtidig fremhever verdien av å «se ting fra et annet menneskes ståsted, kunne tolke handlinger i en annen kultur med utgangspunkt $i$ denne kulturen og betrakte andre kulturer like nyansert som man betrakter egen kultun (Dypedahl \& Eschenbach, 2014, s. 159, mine kursiveringer). Sitatet finner gjenklang iThue Vold (2014), som fremhever evnen "til å ta en annens perspektiv» (s. 5), og dessuten i Haukås \& Thue Vold (2012): «Den interkulturelle tilnærmingen handler om at elevene, gjennom å lære et nytt språk og gjøre erfaringer fra møter med andre kulturer, skal eksponeres for andre måter å se verden på og etter hvert bli $i$ stand til å ta 'den andres' perspektiv» (s. 396, min kursiv). ${ }^{7}$

De siterte passasjene har en didaktisk målsetning som tilsynelatende er i tråd med Kunnskapsløftets vektlegging av demokrati og internasjonal bevissthet. Like fullt mener jeg det er verdt å stille spørsmål ved hvorfor ikke Dypedahl \& Eschenbach eller Haukås \& Thue Vold problematiserer disse påstandene, som innenfor flere teoretiske og filosofiske rammeverk vil innebære en strukturell eller epistemologisk umulighet. Eksempelvis kan vi med Michel Foucault påpeke hvordan de nevnte forskerne overser at våre perspektiver nødvendigvis er begrenset av ulike diskurser og epistemer. Mer problematisk i vår interkulturelle sammenheng er det at disse sitatene viderefører det Spivak i forlengelsen av Foucault kaller «epistemisk vold», og som hun i «Can the Subaltern Speak?» forklarer med hvordan Vesten har gjort seg skyldig i en «persistent constitution of Other as the self's shadow» (1988, s. 75). Med andre ord:

\footnotetext{
${ }^{7}$ Det å skulle ta «den andres» perspektiv er for øvrig en utbredt målsetting innenfor både tradisjonell kulturdidaktikk og pedagogisk pensumlitteratur for lærerstudenter (se for eksempel Manger, Lillejord, Nordahl \& Helland, 2015, s. 75 og s. 182). I sistnevnte sammenheng inngår målsettingen om å ta "den andres» perspektiv gjerne $\mathrm{i}$ et overordnet fokus på anerkjennelse og et positivt læringsmiljø. Når det overføres til en interkulturell sammenheng, får målsettingen imidlertid en postkolonial og/eller geopolitisk klangbunn som gjør den (enda) mer problematisk.
} 


\section{Hans Facob Ohldieck}

Vesten har i lang tid fremstilt «den andre» som sitt eget vrengebilde, sin egen negasjon. Dette innebærer at man måler andre kulturer ut fra ens egne parametere for skikk og bruk, noe som samtidig vil si at «den andre» tenkes som transparent og tilgjengelig for et vestlig blikk, uten at man samtidig problematiserer hvordan ulike verdinormer har oppstått innenfor ulike kulturelle horisonter.

Begrepet om «den andre» viser i denne sammenhengen til en postkolonial ramme, og særlig til Edward Saids Orientalism (1978), hvor Said argumenterer for at Vestens selvbilde er skapt gjennom en negerende relasjon til Orienten/Østen (først og fremst Midtøsten), som nettopp reises som Vestens monstrøse andre gjennom en rekke motsetningspar: Orientens folk er barbariske, vi er siviliserte, de er irrasjonelle, vi er rasjonelle, de er onde, vi er gode, osv. Det er altså i et «kulturnegerende» perspektiv både Said og Spivak omtaler "den andre», og i en slik forståelse er den uttalte ambisjonen om at eleven skal «bli i stand til å ta 'den andres' perspektiv» på ingen måte uskyldig: Den innebærer nødvendigvis en tro på at man skal kunne tilegne seg «den andres» erfaring, og slik bli i stand til å definere - og tale på vegne av - «den andre», en ambisjon som har lange røtter i vestlig imperialistisk tradisjon.

Ut fra Spivaks teoretiske horisont vil det også være problematisk å hevde at «den litterære teksten representerer det generelle gjennom det individuelle» (Fenner, 2011, s. 42) eller å betrakte den litterære teksten som "the personal voice of a culture» (Fenner, 2001, s. 16). Denne formen for assimilering av annetheten i en enhetlig, homogen størrelse eller identitet, er blitt behørig kritisert av Spivak, blant annet i "Can the Subaltern Speak?». Annetheten får et homogent ansikt som lar seg representere av en forfatter, og slik øves det vold på den heterogeniteten eller multiplisiteten som annetheten utgjør. ${ }^{8}$

De forskerne jeg har sitert i de foregående avsnittene, er blant de toneangivende når det gjelder «interkulturell kompetanse» som forskningsfelt i Norge, og etter mitt syn viser ambisjonen om å skulle ta «den andres» perspektiv hvorfor feltet kan ha nytte av å åpne seg for teoretiske impulser som tilnærmer seg annetheten på andre måter. Kramsch bringer også i denne sammenhengen interessante tanker på banen, tanker som i stor grad er inspirert av postkolonialt tankegods, først og fremst Homi Bhabhas begreper om «third space» og hybriditet. Når Kramsch vektlegger hvordan hybride identitetskonstruksjoner kan skapes gjennom kulturmøter, har dette en åpenbar didaktisk verdi, og bl.a. Skalle, Gjesdal og Tveit (2014) har skrevet om hvordan hybriditet kan knyttes til migrantnarrativer på måter som ivaretar hensynet til interkulturell forståelse. Hybriditetsfokuset er samtidig en fremtredende side ved de siste tiårenes «cultural studies» - med særlig forankring i USA-amerikansk akademia som er blitt behørig kritisert av blant andre den chilenske kulturkritikeren Nelly

\footnotetext{
${ }^{8}$ Det skal nevnes at Fenner også vektlegger den bakhtinske polyfonien i denne sammenhengen, noe som kan peke i retning av mangfold/heterogenitet: "Both cultures in the encounter must also be regarded as dynamic and polyphone; any culture is 'a living mix of varied and opposing voices' (Bakhtin, 1984), and learners have to acknowledge this also when it comes to their own culture» (2012, s. 278).
} 
Richard (1997). Ifølge Richard bidrar fokuset på hybriditet, kreolisering, transkulturasjon og lignende begreper til å dekke over maktforskjellene mellom metropol og periferi i globaliseringens tidsalder, ved at det skapes et harmonisk inntrykk av trans-kulturelle forbindelser. På tilsvarende måte gis metropolen anledning til å appropriere periferien - eller tale på dens vegne - siden hybriditetsfokuset skaper inntrykk av at man er forent $\mathrm{i}$ en høyere enhet. Slik reaktualiseres universalistisk tankegods, og ifølge kritikken spiller denne formen for kulturstudier dessuten på lag med økonomiske interesser, som på lignende vis benytter hybride strategier for å få tilgang til nye markeder.

I lys av dette er det interessant at Kramsch også siterer Spivak, som vektlegger det langsiktige perspektivet ved utdanningen innenfor humaniora, for slik å kunne utvikle ansvarlighet overfor annetheten (alterity) som et etisk imperativ. Denne målsettingen har i stor grad sitt grunnlag i Jacques Derrida og Émmanuel Levinas som begge fremhever denne formen for ansvarlighet, og der altérité knyttes til en absolutt annethet, en forskjell (différenceldifférance) eller det Édouard Glissant (1997) kaller en opasitet som vi aldri fullt og helt kan overkomme. Mens tradisjonell fenomenologi opererer innenfor det Derrida kaller l'empire du propre, det sammes imperium, ved at «den andre» alltid er underlagt selvets forståelseshorisont, ligger ansvarligheten overfor annetheten $\mathrm{i}$ en grunnleggende respekt for at «den andre» aldri lar seg assimilere innenfor vårt meningsparadigme. "Den andre» lar seg aldri fullt og helt forstå, og dermed lar hun/han seg heller ikke fastholde innenfor et tradisjonelt vestlig bilde av «den andre» som vår egen dialektiske motsats. Kramsch utlegger på følgende måte hva dette vil ha å si for lærere i fremmedspråk (FL): «FL educators are in charge of the primary health care of their students and means showing, modeling, performing, and helping them perform the uncoercive rearrangement of [their] desire - which Spivak sees as the very goal of the humanities» (Kramsch, 2014, s. 308). Ifølge Spivak (og Kramsch) har altså lærerne i fremmedspråk et tungt ansvar innenfor det som er humanioras primære oppgave: å utvikle en «ikke-tvingende omorganisering av begjæret». Hva innebærer det? Det innebærer å bidra til å åpne nye kanaler for elevenes begjærsstrømmer, forestillingsevne og nysgjerrighet, nettopp ved at eleven erfarer hvordan «den andre» ikke lar seg holde fast av våre kategorier og definisjoner, og at dette heller ikke er ønskelig. Slik åpnes det for en reell ansvarlighet overfor annetheten, og slik legges dessuten grunnlaget for at man også selv kan forandres.

Denne formen for ansvarlighet overfor annetheten er grunnleggende for min egen forståelse av interkulturell kompetanse, og da er vi langt fra Bøhn \& Dypedahls definisjon, og også langt fra målsettingen om å "ta 'den andres' perspektiv». I en globalisert verden handler det snarere om å motstå det imperialistiske begjæret etter å assimilere «den andre», for på denne måten kan man skape det Spivak kaller "planetarity», som er et alternativ til «globalization». Mens sistnevnte term er uløselig forbundet med økonomisk, politisk og kulturell imperialisme, er førstnevnte et etisk motsvar der heterogeniteten bevares, både i og utenfor oss selv: «If we imagine ourselves as planetary subjects rather than global agents, planetary creatures rather than 


\section{Hans facob Ohldieck}

global entities, alterity remains underived from us; it is not our dialectical negation, it contains us as much as it flings us away» (2003, s. 73). Som vi ser av sitatet, er det nettopp gjennom en ansvarlighet overfor annetheten at vi selv kan la oss forandre, og at vi selv kan ta del i ukjente meningsuniverser uten imperialistisk begjær etter å assimilere.

I tillegg til det etiske imperativet er altså "planetarity» et begrep som innebærer at vår egen flerstemmighet styrkes, og slik er det også i tråd med Kunnskapsløftets vektlegging av demokratisk forståelse. Deleuze og Guattaris interesse for Bakhtin stammer nettopp fra et slikt perspektiv, der Bakhtins begreper om polyfoni og flerstemmighet - som hyppig anvendes i didaktisk forskning - ses i forbindelse med vårt eget mangfold av begiærsstrømmer. Selv om Spivak er kritisk til deler av Deleuzes tenkning omkring "den andre», er det her klare paralleller mellom dem, paralleller som vil kunne være berikende innenfor rammen av litteratur- og fremmedspråksdidaktikk. For begge handler det om å bevare den indre og ytre multiplisiteten, og for begge handler det likeledes om å endre begjærets «kulturelle infrastruktur» (Spivak) eller «kartografi» (Deleuze), mens perspektivet er rettet mot hva vi er i stand til å bli: Deleuzes begrep om devenir/becoming får sitt motstykke i Spivaks Derrida-inspirerte begrep om et samfunn to come, i klar kontrast til det mer tradisjonelle subjekt- og meningsbaserte fokuset på interkulturell kompetanse som en dialogisk utspørring av vår egen og "den andres» identitet.

Både for Deleuze og Spivak spiller skjønnlitteraturen en vesentlig rolle i denne sammenhengen. Når det gjelder Spivaks forbindelse mellom skjønnlitteraturen og "den andre», skriver hun som følger:

[T] he teacher can try to rearrange desires uncoercively [...] through an attempt to develop in the student a habit of literary reading, even just "reading," suspending oneself into the text of the other [...]. A training in literary reading is a training to learn from the singular and the unverifiable. Although literature cannot speak, this species of patient reading, miming an effort to make the text respond, as it were, is a training not only in poiesis, accessing the other so well that probable action can be prefigured, but teleo-poesis, striving for a response from the distant other, without guarantees (2004, s. 532).

Spivak betoner her den langsomme og uopphørlige leseprosessen, som ikke gir noen garantier eller endelige svar, siden skjønnlitteraturen - en form for altérité - ikke lar seg uttømme. Slik blir også den litterære/retoriske figuren sentral for Spivak: I likhet med "den andre» er figuren flertydig og lar seg ikke holde fast. Gjennom øvelse i figurlige lesninger kan leseren motstå den mer tradisjonelle - og assimilerende - formen for «identity politics» og også det globaliserte markedets behov for gjennomsiktighet. Spivak skriver: "All around us is the clamor for the rational destruction of the figure, the demand for not clarity but immediate comprehensibility by the ideological average. This destroys the force of literature as a cultural good» (2003, s. 71). A sørge for at skjønnlitteraturen fortsetter å være et «cultural good» i en globalisert tidsalder, innebærer å tenke innenfor "planetaritetens» modus, forankret $i$ et ansvar overfor 
annetheten som er "sensed before sense as a call of the other» (2004, s. 535). Med andre ord: Affekten er primær. Den utgjør en uklar erkjennelse, en pathos, som er grunnleggende for oss som mennesker, inkludert fremmedspråkslærere som jobber for en «ikke-tvingende omorganisering av begiæret». Dermed er den også grunnleggende for en mer åpen, nysgjerrig og ansvarlig tilnærming til «den andre» innenfor kulturelle termer.

\section{Avsluttende refleksjoner}

Jeg har i denne artikkelen belyst hvordan ambisjonen om å skulle "ta 'den andres' perspektiv» (i beste fall) undervurderer de hegemoniske narrativenes kraft innenfor vår egen nasjonale diskurs og verdinorm. Samtidig er det bemerkelsesverdig hvor utbredt denne ambisjonen er innenfor fremmedspråksdidaktikken i Norge, og hvor uproblematisk subjektet synes å være i de fremstillingene som målbærer denne ambisjonen. Disse svakhetene er tett forbundet med det jeg anser for å være problematiske sider ved den norske litteraturdidaktikken generelt, som jeg mener hemmes av reader response-teorienes dominerende posisjon.

Det sterke fokuset på lesersubjektet går på bekostning av åpenheten for annetheten både i estetisk og interkulturell forstand. Jeg mener dette også gjelder Fenners hermeneutiske ståsted, selv om Fenner i langt større grad enn for eksempel Vestli tar på alvor litteraturens fremmedgjørende aspekter. Subjektet settes ikke radikalt på spill innenfor det fenomenologiske og hermeneutiske registeret, og dette gienspeiles i Fenners positive vurdering av hvordan den litterære teksten kan representere "det generelle gjennom det individuelle», et ståsted jeg selv mener kan bidra til å homogenisere «den andre» i fremmedspråksundervisningen. Når Spivak snakker om humanioras "uncoercive rearrangement of [their] desire», eller Deleuze om den litterære hendelsen, er vi et annet sted: Her handler det om en sensibilitet som er affektivt fundert, som ivaretar pluraliteten og flerstemmigheten, og som - i enda større grad enn Kramsch - tar på alvor den estetiske dimensjonen ved dagens globaliserte virkelighet. Dette har betydning for litteraturdidaktikken generelt, men særlig for fremmedspråksdidaktikken, der utviklingen av interkulturell forståelse blir et stadig viktigere kompetansemål.

Skjønnlitteraturen er i dag under sterkt press i fremmedspråksundervisningen, der den ser ut til å tape terreng i forhold til mer fakta-/ sakprosaorienterte autentiske tekster. Dersom skjønnlitteraturen skal forsvare sin faglige posisjon i dagens globaliserte tidsalder, må de affektive kvalitetene fremheves, og man må våge å utforske teorier som setter subjektet radikalt i spill. På den måten er en reell interkulturell kompetanse mulig, og slik kan man unngå å assimilere "den andre» under selvets imperialistiske horisont. Dette ståstedet krever nytenkning i forhold til litteraturutvalget man presenterer elevene for, men først og fremst krever det bevisstgiøring omkring følgende faktum: Når det gjelder interkulturell kompetanse, er affektiv læring også den mest effektive. 


\section{Hans Facob Ohldieck}

\section{Biografi}

Hans J. Ohldieck er førsteamanuensis i spansk og latinamerikansk kultur og litteratur ved Institutt for språk og litteratur, Universitetet i Sørøst-Norge. Medredaktør av tidsskriftet Karib - Nordisk tidsskrift for Karibiaforskning. Blant hans seneste publikasjoner er "Kulturkritikk av volden? Begivenhet, tilblivelse og det reelle» (Kultur og klasse 122/2016, med Gisle Selnes), "Calibans kamp: om Frantz Fanon og Karibia» (Agora 1/2017) og Deleuze og foldens filosofi via Herman Melville og Orson Welles» (Deleuze iVest, Morgana Press, 2018).

\section{Referanser}

Andersen, H.L., Lund, K., \& Risager, K. (2006). Introduction. Culture in Language Learning (s. 7-11). Aarhus: Aarhus University Press.

Bhabha, H. (2010 [1994]). The Location of Culture. London: Routledge.

Blommaert, J. (2010). The Sociolinguistics of Globalization. Cambridge: Cambridge University Press.

Bredella, L. (2004). Literary Texts. I M. Byram (Red.), Routledge Encyclopedia of Language Teaching and Learning (s. 375-382). London og New York: Routledge.

Bugge, H.-E. (2011). Utvikling av interkulturell kompetanse og språkopplæring - to sider av samme sak. Communicare, 1, 4-10.

Byram, M. (1997). Teaching and Assessing Intercultural Communicative Competence. Clevedon: Multilingual Matters Ltd.

Bøhn, H., \& Dypedahl, M. (2009). Veien til interkulturell kompetanse. Bergen: Fagbokforlaget.

Council of Europe (2001). Common European Framework of Reference for Languages: Learning, Teaching, Assessment. Council of Europe, Modern Languages Division, Strasbourg. Cambridge: Cambridge University Press.

Deleuze, G. (1983). Cinéma 1 - L'image-mouvement. Paris: Les Éditions du Minuit.

Deleuze, G. (2005). Litteraturen og livet. Oversatt av I. Nielsen. I Audiatur - Katalog for ny poesi, Bergen 13.-16. oktober 2005 (s. 213-218). Bergen: Audiatur.

Deleuze, G. \& Guattari, F. (1987). A Thousand Plateaus: Capitalism and Schizophrenia. Oversatt og med forord av Brian Massumi. Minneapolis/London: University of Minnesota Press.

Deleuze, G., \& Guattari, F. (2008). Persept, affekt og konsept. I K. Bale, \& A. Bø-Rygg, Estetisk teori-en antologi (s. 491-519). Oslo: Universitetsforlaget.

Dypedahl, M. \& Eschenbach, J. (2014). Interkulturell kompetanse i språkundervisningen. Kap. 11 i Bjørke, C., Dypedahl, M., \& Myklevold, G.-A. (Red). Fremmedspråksdidaktikk (s. 157-168). Oslo: Cappelen Damm.

Eide, L. (2012). Representasjoner av målspråksområdet i fremmedspråksfaget. En studie av Latin-Amerika i lcerebøker $i$ Spansk. PhD-avhandling ved Universitetet i Bergen.

Fenner, A.-B. (2001). Dialogical interaction with literary texts in the lower secondary classroom. I A.-B Fenner (red.): Cultural awareness and language awareness based on dialogical interaction with texts in foreign language learning (s. 13-46). Strasbourg: ECML/Council of Europe Publishing.

Fenner, A.-B. (2008). Cultural Awareness in the Foreign Language Classroom. I Cenoz, \& Hornberger (Red.), Encyclopedia of Language and Education, Vol. 6: Knowledge about Language (s. 273-285). New York: Springer.

Fenner, A.-B. (2011). Litteraturens rolle i utviklingen av interkulturell kompetanse. Communicare, nr. 1. Østfold: Høgskolen i Østfold, 41-43.

Glissant, E. (1997). Le discours antillais. Paris: Gallimard.

Haukås, Å., \& Thue Vold, E. (2012). Internasjonale trender innen fremmedspråksdidaktisk forskning. Norsk pedagogisk tidsskrift, 5, 386-401.

Iser, W. (1980). The Act of Reading. A Theory of Aesthetic Response. Baltimore: John Hopkins University Press.

Kramsch, C. (1993). Context and Culture in Language Teaching. Oxford: Oxford University Press.

Kramsch, C. (2006). Culture in Language Teaching. I Culture in Language Learning (s. 11-27). Aarhus: Aarhus University Press.

Kramsch, C. (2010). The Symbolic Dimensions of the Intercultural. Cambridge: Cambridge University Press. doi: $10.1017 / \mathrm{S} 0261444810000431$

Kramsch, C. (2014). Teaching Foreign Languages in an Era of Globalization: Introduction. The Modern Language fournal, 98(1), 296-311. doi: 10.1111/j.1540-4781.2014.12057. 
Manger, T., Lillejord, S., Nordahl, T. \& Helleland, T. (2015). Livet i skolen 1. Grunnbok i pedagogikk og elevkunnskap: Undervisning og lcering. Bergen: Fagbokforlaget.

Massumi, B. (2002). Movement, Affect, Sensation. Parables for the Virtual. Durham \& London: Duke University Press.

Olsbu, I. (2014). The Future of Literary Texts in the L3 Classroom. Acta Didactica, 8(2), art. 10. doi: http:// dx.doi.org/10.5617/adno.1133

Paefgen, E. (1999). Einführung in die Literaturdidaktik. Stuttgart: Metzler.

Rancière, J. (2000). Le partage du sensible. Paris: Fabrique Éditions.

Regjerningen (2017) Overordnet del - verdier og prinsipper for grunnopplæringen. Hentet fra: https://www. regjeringen.no/contentassets/53d21 ea2bc3a4202b86b83cfe82da93e/overordnet-del---verdier-og-prinsipperfor-grunnopplaringen.pdf

Richard, N. (1997). Intersectando Latinoamérica con el latinoamericanismo: Discurso académico y crítica cultural. Revista Iberoamericana, vol. LXIII, nr. 180, juli -september, 345-361.

Risager, K. (2004). Den fælles europæiske referenceramme for sprog: Et værktøj med begrænsninger. Sprogforum - Tidsskrift for sprog- og kulturpcedagogik, 31 .

Rivers, J. (2010). An Introduction to the Concept of Intercultural Communicative Language Teaching and Learning: A Summary for Teachers. Wellington, NZ: Ministry of Education.

Shanahan, D. (1997). Articulating the Relationship between Language, Literature, and Culture: Toward a New Agenda for Foreign Language Teaching and Research. The Modern Language fournal, 81(2), $164-174$.

Skalle, C., A. Gjesdal \& H. Tveit (2015). Migrantnarrativer i fremmedspråksundervisning og utvikling av interkulturell kompetanse. Norsk Pedagogisk Tidsskrift, 3-4, 256-267.

Skulstad, A. (2012). Trender i postmetodenes tidsalder i engelsk fagdidaktikk. Norsk Pedagogisk Tidsskrift, 4, 317-328.

Spivak, G.C. (1988). "Can the Subaltern Speak?». I Nelson, C \& Grossberg, L. (Red.), Marxism and the Interpretation of Culture (s. 271-313). Basingstoke: Macmillan Education.

Spivak, G.C. (2003). Death of a Discipline. New York: Columbia University Press.

Spivak, G.C. (2004). «Righting Wrongs». The South Atlantic Quarterly, 103(2/3).

Thue Vold, E. (2014). Instrumentelt turistspråk eller interkulturell dannelse? Om fremmedspråkfagets formål i dag og frem mot 2030. Acta Didactica, 8(2), art. 8.

Tornberg, U. (2013). What counts as «knowledge» in foreign language teaching and learning practices today? Foreign Language pedagogy as a mirror of its time. Nordic fournal of Modern Language Methodology.

Vestli, E.N. (2008). Fra sokkel til klasserom. Litteraturens plass i fremmedspråksundervisningen (i bokserien Fokus på språk, vol. 13). Halden: Fremmedspråksenteret, Høgskolen i Østfold.

Wiland, S.M. \& Ibsen, E. (2000). Encounters with Literature - The Didactics of English Literature in the Context of the Foreign Language Classroom in Norway. Oslo: Cappelen Damm Høyskoleforlaget.

Wiland, S.M. (2007). Poetry: Prima Vista. Reader-Response Research on Poetry in a Foreign Language Context. Avhanding for dr. art.-grad ved Universitetet i Bergen. 